\title{
Industry funding of patient and health consumer organisations: systematic review with meta-analysis
}

\author{
Alice Fabbri, ${ }^{1}$ Lisa Parker, ${ }^{1}$ Cinzia Colombo, ${ }^{2}$ Paola Mosconi, ${ }^{2}$ Giussy Barbara, ${ }^{3}$ \\ Maria Pina Frattaruolo, ${ }^{3}$ Edith Lau, ${ }^{1}$ Cynthia M Kroeger, ${ }^{1}$ Carole Lunny, ${ }^{4}$ Douglas M Salzwedel, ${ }^{4}$ \\ Barbara Mintzes ${ }^{1}$
}

${ }^{1}$ Charles Perkins Centre and School of Pharmacy, Faculty of Medicine and Health,

The University of Sydney, Camperdown, Sydney, NSW 2006, Australia

${ }^{2}$ Laboratory of Medical Research on Consumer Involvement, Department of Public Health, Istituto di Ricerche Farmacologiche Mario Negri IRCCS, Milan, Italy

${ }^{3}$ Gynaecology Unit, Fondazione IRCCS Ca' Granda, Ospedale Maggiore Policlinico, Milan, Italy

${ }^{4}$ Cochrane Hypertension

Review Group, Therapeutics

Initiative, Department of

Anesthesiology, Pharmacology, and Therapeutics, Faculty of

Medicine, University of British

Columbia, Vancouver, BC,

Canada

Correspondence to: B Mintzes barbara.mintzes@sydney.edu.au (ORCID 0000-0002-8671-915X) Additional material is published online only. To view please visit the journal online.

Cite this as: $B M J$ 2020;368:16925 http://dx.doi.org/10.1136/bmj.16925

Accepted: 4 December 2019

\section{ABSTRACT}

OBJECTIVE

To investigate pharmaceutical or medical device industry funding of patient groups.

DESIGN

Systematic review with meta-analysis.

DATA SOURCES

Ovid Medline, Embase, Web of Science, Scopus, and Google Scholar from inception to January 2018; reference lists of eligible studies and experts in the field.

\section{ELIGIBILITY CRITERIA FOR SELECTING STUDIES}

Observational studies including cross sectional, cohort, case-control, interrupted time series, and before-after studies of patient groups reporting at least one of the following outcomes: prevalence of industry funding; proportion of industry funded patient groups that disclosed information about this funding; and association between industry funding and organisational positions on health and policy issues. Studies were included irrespective of language or publication type.

\section{REVIEW METHODS}

Reviewers carried out duplicate independent data extraction and assessment of study quality. An amended version of the checklist for prevalence studies developed by the Joanna Briggs Institute was used to assess study quality. A DerSimonian-Laird

\section{WHAT IS ALREADY KNOWN ON THIS TOPIC}

Patient groups play an important part in healthcare: educating consumers, funding medical research, and contributing to decisions on approval and public coverage of drugs and treatments

Patient groups often rely on multiple sources of financial support, including the pharmaceutical and medical device industries

Concerns have been raised about the financial relationships between industry and patient groups because of conflicts of interest and potential threats to the integrity and independence of groups

\section{WHAT THIS STUDY ADDS}

Industry funding of patient groups is common in many high income countries and in different clinical areas, but the extent of industry funding of patient groups in low and middle income countries is unknown

Few patient groups have policies that govern corporate funding and transparency is inadequate

Studies that examined associations between funding status and policy positions were limited but reported that industry funded groups generally supported sponsors' interests

Conclusions that could be drawn are limited by the low quality of available data on key study outcomes estimate of single proportions with Freeman-Tukey arcsine transformation was used for meta-analyses of prevalence. GRADE (Grading of Recommendations Assessment, Development, and Evaluation) was used to assess the quality of the evidence for each outcome.

\section{RESULTS}

26 cross sectional studies met the inclusion criteria. Of these, 15 studies estimated the prevalence of industry funding, which ranged from 20\% (12/61) to $83 \%(86 / 104)$. Among patient organisations that received industry funding, $27 \%(175 / 642 ; 95 \%$ confidence interval $24 \%$ to $31 \%$ ) disclosed this information on their websites. In submissions to consultations, two studies showed very different disclosure rates ( $0 \%$ and $91 \%$ ), which appeared to reflect differences in the relevant government agency's disclosure requirements. Prevalence estimates of organisational policies that govern corporate sponsorship ranged from $2 \%(2 / 125)$ to $64 \%$ $(175 / 274)$. Four studies analysed the relationship between industry funding and organisational positions on a range of highly controversial issues. Industry funded groups generally supported sponsors' interests.

\section{CONCLUSION}

In general, industry funding of patient groups seems to be common, with prevalence estimates ranging from $20 \%$ to $83 \%$. Few patient groups have policies that govern corporate sponsorship. Transparency about corporate funding is also inadequate. Among the few studies that examined associations between industry funding and organisational positions, industry funded groups tended to have positions favourable to the sponsor. Patient groups have an important role in advocacy, education, and research, therefore strategies are needed to prevent biases that could favour the interests of sponsors above those of the public.

\section{SYSTEMATIC REVIEW REGISTRATION} PROSPERO CRD42017079265.

\section{Introduction}

Patient and health consumer groups (referred to as "patient groups") are non-profit organisations that aim to focus on the needs and interests of patients and communities affected by a specific disease or condition, or of health service users more generally. ${ }^{1}$ The size of these groups can vary widely from small organisations run by volunteers to big national organisations with salaried staff and thousands of members. Patient groups carry out many activities, such as providing 
direct support, services, and education to patients and health consumers; funding of and participating in medical research; contributing to guideline development; and advocating for policies related to health services or health products. For example, when advocating for policies, groups might lobby for patient access or government subsidy for drugs and devices. For some diseases (eg, HIV), patient groups were also instrumental in lowering the price of drugs by taking positions that did not align with the manufacturers of HIV and AIDS drugs. ${ }^{2}$

Patient groups often rely on multiple sources of financial support, including the pharmaceutical and medical device industries. In recent years, concerns have been raised about financial relationships between patient groups and the pharmaceutical or medical device industries because of conflicts of interest and potential threats to the integrity, credibility, and independence of groups. ${ }^{34}$

In some areas, such as access to and subsidy for drugs, the interests of the two parties might align; however, industry funding places patient groups in a conflict of interest situation. The primary interest of pharmaceutical and device companies is to maximise profits, which can conflict with the mission of patient groups to protect the welfare of the people they represent. ${ }^{5}$ Industry funded groups might, consciously or unconsciously, undertake advocacy, education, training, and research activities that echo their sponsors' interests. ${ }^{6}$ Industry funding might also work more subtly, nudging the sector towards a particular

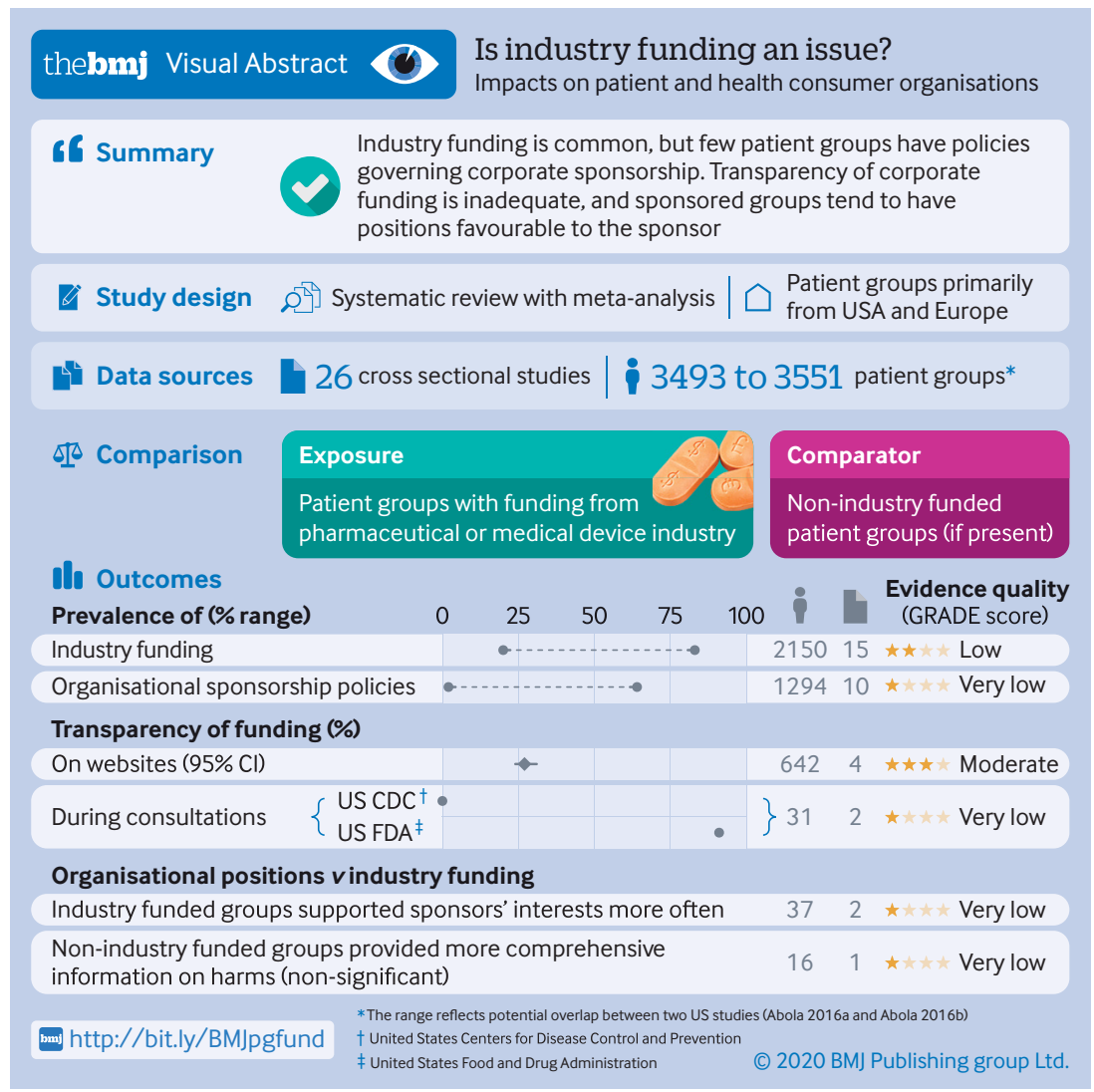

emphasis. Assuming that industries will target groups and activities that further their interests, a culture of industry funding within a diverse patient group sector might selectively enhance the patient group voices that align with industry priorities. ${ }^{3}$ These concerns raise several questions about the extent and impact of industry funding of patient groups.

In recent years, increasing attention has been paid to these interactions, which has been demonstrated by the development of educational programmes, ${ }^{7}$ codes, and guidelines. ${ }^{8-11}$ These documents have usually been developed by representatives of patient groups and the pharmaceutical industry, and list principles for collaborations such as transparency, respect for independence, confidentiality, and accountability. Research evidence on the nature and frequency of pharmaceutical industry sponsorship of patient groups is also growing. ${ }^{12-15}$ However, systematic reviews in this research area are lacking. The aim of this review was to investigate industry funding of patient groups.

\section{Methods}

\section{Protocol, search strategy, and study selection}

The protocol was published in PROSPERO (CRD42017079265) before we carried out the review, and includes additional details about prespecified methods. We searched the following databases (from inception to 20 January 2018): Ovid Medline, Embase, Web of Science, Scopus, and Google Scholar. Supplementary file 1 describes the search strategy for each database. We also hand searched the reference lists of included studies and contacted experts in the field to identify additional studies.

The eligibility criteria for studies included in this review were as follows:

- Study design: observational studies with cross sectional, cohort, case-control, interrupted time series, and before-after designs.

- Population: patient groups, including non-profit patient organisations that aim to represent the interests of patients at risk or affected by a specific disease or condition, or set of conditions, and nonprofit consumer organisations that advocate for the health rights of people or the interests of health services users.

- Exposure: pharmaceutical or medical device (industry) funding; pharmaceutical companies included producers of medicines, biological drugs, and small molecule drugs (eg, biotechnology industry).

- Comparison groups: non-industry funded patient groups (if present).

- Outcome measures, at least one of the following measures was reported:

- prevalence: proportion of patient groups that accept industry funding, proportion of patient groups' funding that is from industry, and number of funders for each group;

- transparency: proportion of industry funded patient groups that report the source of 
their funding on their websites and during governmental consultations;

- positions: association between industry funding and organisational positions on health and policy issues or organisational policies on conflict of interest.

We excluded editorials, commentaries, systematic reviews, narrative reviews, and studies that only used qualitative methodologies; studies that focused on multiple types of organisations (eg, patient groups and professional organisations) without a separate analysis for patient groups, and for which a breakdown could not be obtained from the study authors; and studies that analysed non-pharmaceutical or medical device industry funding, or studies of mixed funding sources, for which pharmaceutical or medical device industry funding was not reported separately and a breakdown could not be obtained from the study authors.

We did not exclude studies based on language, publication date, or study setting. Four pairs of assessors independently screened the titles and abstracts of all retrieved records for obvious exclusions and then applied our inclusion criteria to the full text of the remaining papers. Any disagreements between the two investigators were resolved by consensus. Supplementary file 2 presents reasons for exclusion of potentially eligible papers. If multiple reports of a study were identified, we considered the most comprehensive report to be the primary data source.

\section{Data extraction}

Four pairs of assessors independently extracted the following data: general study information (author, year of publication, funding source, and authors' conflicts of interest); study design and study population details (location, sample size, response rate, and if applicable, disease area of the included patient groups); year and methods of data collection; and outcomes.

Discrepancies in data extraction were resolved by consensus between the two assessors. If agreement could not be reached, a third assessor adjudicated the outcome. When reporting in published articles was unclear, or data on primary outcome measures were not provided separately for patient groups, we contacted the authors for clarification and to request access to the raw data. We stored all extracted data from the included studies in REDCap, a secure web based application for the collection and management of data. ${ }^{16}$ We contacted the authors of nine papers to obtain extra information or clarification, and all responded. ${ }^{1} 121417-22$

\section{Quality assessment}

All the included studies were cross sectional, and so we used the checklist for prevalence studies developed by the Joanna Briggs Institute to measure quality. ${ }^{23}$ The checklist assesses the quality of a study across nine domains. We amended this tool to reflect the focus on a policy issue rather than a clinical condition and tested it on two studies to achieve agreement among reviewers. We changed the possible answers for each domain from yes, no, unclear, or not applicable to high quality, low quality, unclear, or not applicable (supplementary file 3). The quality assessment is presented in tables by domain and individual study. For the assessment, we considered an entire study to be of low quality if more than one domain was judged as low quality, if one domain was of low quality and any others were unclear, or if more than two domains were judged as unclear.

To assess the quality of evidence, we used GRADE (Grading of Recommendations, Assessment, Development, and Evaluation) for the following outcomes: prevalence of industry funding, proportion of industry funded patient groups that disclosed information about industry funding on their websites and during governmental consultations; prevalence of patient groups' policies governing corporate sponsorship; proportion of groups (industry funded $v$ non-industry funded) with policy positions in sponsors' interests; and comprehensiveness of information on harms provided by industry funded and non-industry funded groups. GRADE assesses the evidence as high, moderate, low, or very low quality based on risk of bias, directness, consistency, precision, and reporting bias. ${ }^{24}$ Observational studies usually start as low quality evidence, but can be upgraded or downgraded according to the GRADE recommendations. Two reviewers independently assessed certainty of evidence for each outcome, and then resolved any discrepancies by consensus.

\section{Statistical analysis}

We undertook an initial descriptive analysis of the studies, including study characteristics and setting. We present the populations, outcomes, and other characteristics of the studies. We conducted a metaanalysis of single proportions for assessed quantitative outcomes (random effects meta-analysis using the DerSimonian-Laird estimate ${ }^{25}$ of single proportions with prevalence estimates that had been transformed using the Freeman-Tukey double arcsine transformation). ${ }^{26}$ Confidence intervals for individual studies were calculated using the Clopper-Pearson method. ${ }^{27}$

Heterogeneity between estimates was assessed using the $\mathrm{I}^{2}$ statistic, and reasons for heterogeneity were explored using subgroup analyses. We interpreted the $\mathrm{I}^{2}$ index as representing low, moderate, or high heterogeneity at thresholds of $25 \%, 50 \%$, and $75 \%$, respectively. ${ }^{28}$ We prespecified the following types of subgroup analyses in the protocol if sufficient data were available: setting (low or middle $v$ high income country according to World Bank classification); disease group (multiple diseases $v$ condition specific studies); funding source (pharmaceutical $v$ medical device industry); proportion of industry funding; and service provision compared with advocacy only organisations (namely, groups that provide direct support to patients $v$ groups that advocate for policies related to health services or health products). Additional post hoc subgroup analyses were conducted to explore 
heterogeneity, including sample size (higher or lower than the median), and timing (before 2010, the midpoint for included studies, or 2010 onwards). We also undertook a subgroup analysis of study quality. Statistical analyses were conducted in R (version 3.5.1) by using the "metaprop" or "metabin" (for the metaanalyses) functions of the "meta" package (version 4.9-3). All data and analysis codes are included in the article or uploaded as supplementary files (supplementary files 4 and 5).

\section{Patient and public involvement}

Two of the study authors (PM and BM) have been involved for many years with women's health and consumer groups and maintain strong community engagement. Both authors assisted in decisions on the research questions to be addressed, protocol development, approach to analysis, and interpretation and reporting of results. Additionally, one representative of a Canadian patient group reviewed and commented on the findings of the review.

\section{Results}

\section{Description of included studies}

Figure 1 shows that 5309 references were identified for screening and 26 studies (included in 27 reports) met the inclusion criteria. Supplementary file 2 contains the list of excluded studies and reasons for exclusion at the full text screening stage. The most common reason for exclusion was study design (not research, eg, commentaries or editorials; $n=43$ ), followed by outcomes of interest not reported $(n=14)$.
Table 1 summarises the characteristics of the included studies. The 26 studies were published between 2003 and 2018 and were all cross

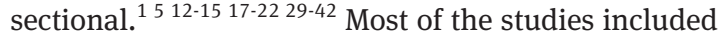
patient groups from multiple disease areas and were conducted in high income countries, primarily the United States and Europe. Several studies used data collected from multiple sources, such as questionnaire surveys, websites, or documents analysis; others relied only on a single data source. Survey response rates ranged from $39 \%$ to $87 \%$. Sample sizes for each study also varied greatly, from eight to $1215 .^{2234}$

Table 2 presents the findings for all the outcomes. We meta-analysed the following outcomes: prevalence of industry funding; proportion of industry funded patient groups that disclosed information about industry funding on their websites; and prevalence of patient group policies that govern corporate sponsorship. We could not conduct several subgroup analyses because of a lack of data: setting (low or middle $v$ high income country); funding source (pharmaceutical $v$ medical device industry); proportion of industry funding; and service provision versus advocacy only organisations. Because of the high level of unexplained heterogeneity, we cannot meaningfully present summary estimates for prevalence of industry funding and prevalence of organisational policies. Supplementary file 4 lists all the analyses that we conducted.

\section{Quality of included studies}

Figure 2 shows the quality assessment for each included study. Nine studies were assessed to be of high quality

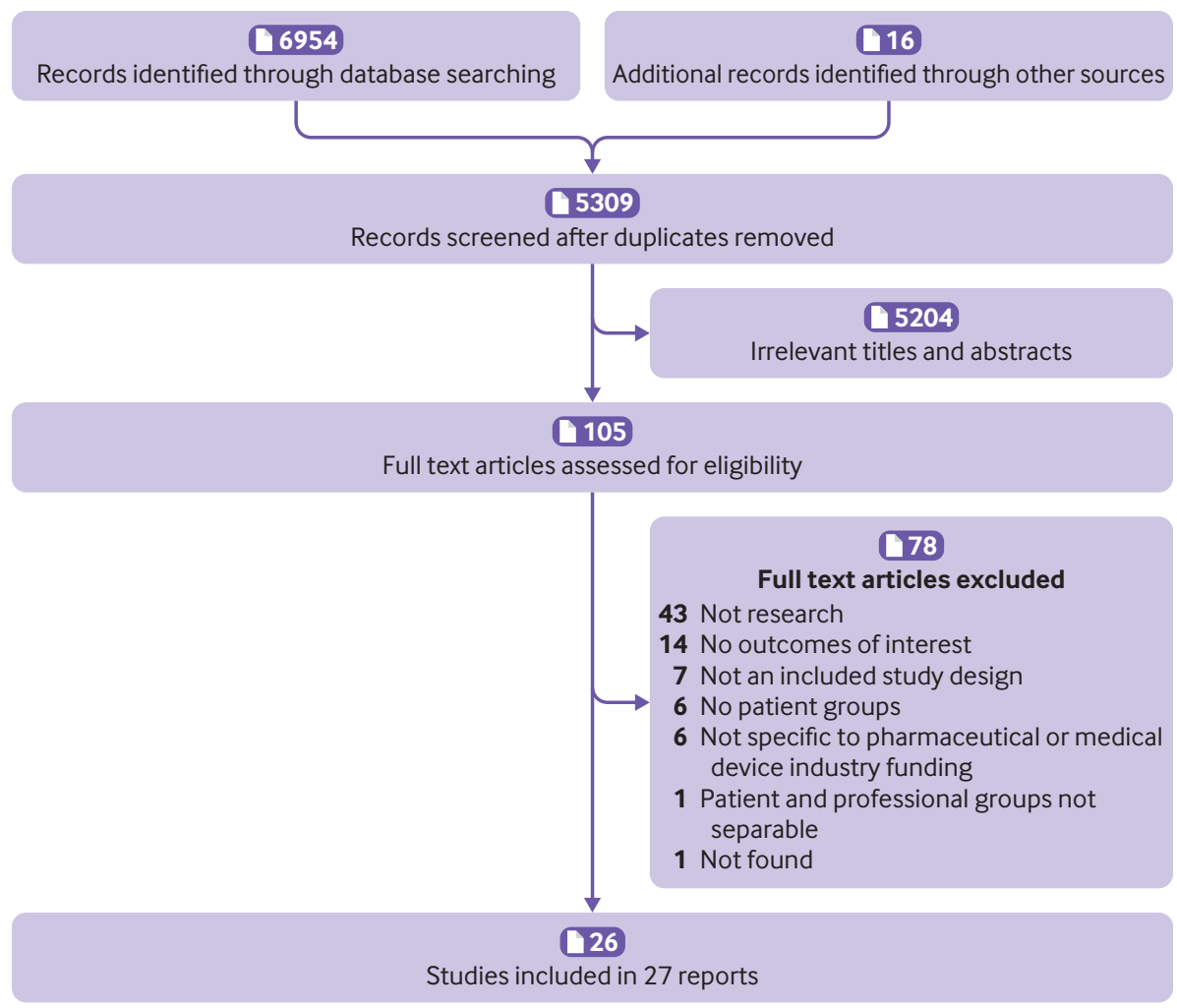

Fig 1 | PRISMA (preferred reporting items for systematic reviews and meta-analyses) flow diagram of included articles 


\section{Table 1 | Characteristics of studies included in systematic review of industry funding of patient groups}

\begin{tabular}{|c|c|c|c|c|c|c|c|c|}
\hline Study* & $\begin{array}{l}\text { Location of study } \\
\text { sample }\end{array}$ & $\begin{array}{l}\text { No of patient } \\
\text { groupst }\end{array}$ & $\begin{array}{l}\text { Disease } \\
\text { focus } ¥\end{array}$ & $\begin{array}{l}\text { Year of data } \\
\text { collection }\end{array}$ & $\begin{array}{l}\text { Data collection } \\
\text { methods } \S\end{array}$ & $\begin{array}{l}\text { Publication } \\
\text { type }\end{array}$ & $\begin{array}{l}\text { Funding } \\
\text { source }\end{array}$ & $\begin{array}{l}\text { Author } \\
\text { conflicts of } \\
\text { interest? }\end{array}$ \\
\hline Abola 2016a & US & 68 & Cancer & 2015-16 & Websites & $\begin{array}{l}\text { Peer reviewed } \\
\text { journal }\end{array}$ & Not reported & Not reported \\
\hline Abola 2016b & US & 58 & Cancer & 2015 & FDA meeting transcripts & $\begin{array}{l}\text { Peer reviewed } \\
\text { journal }\end{array}$ & Not reported & No \\
\hline Anonymous 2003 & UK & 125 & Multiple & Not reported & Websites & Lay press & Non-profit & Not reported \\
\hline Baggott 2005 & UK & $123 / 186(66 \%)$ & Multiple & 1999 & Questionnaires & Academic book & Government & Not reported \\
\hline Baggott $2014^{\star *}$ & UK & $122 / 312(39 \%)$ & Multiple & 2010 & Questionnaires & $\begin{array}{l}\text { Peer reviewed } \\
\text { journal }\end{array}$ & Not reported & Not reported \\
\hline Ball 2006 & $\begin{array}{l}\text { Various (US, UK, } \\
\text { Australia, Canada and } \\
\text { South Africa) }\end{array}$ & 69 & Multiple & 2005 & Websites & $\begin{array}{l}\text { Peer reviewed } \\
\text { journal }\end{array}$ & $\begin{array}{l}\text { No funding } \\
\text { received }\end{array}$ & No \\
\hline Claypool 2016 & US & 147 & Multiple & 2016 & $\begin{array}{l}\text { Websites (patient } \\
\text { groups and } \\
\text { pharmaceutical } \\
\text { companies), } \\
\text { transparency databases }\end{array}$ & Report & Not reported & Not reported \\
\hline Colombo 2012 & Italy & 157 & Multiple & 2010 & $\begin{array}{l}\text { Websites (patient } \\
\text { groups and pharmaceu- } \\
\text { tical companies) }\end{array}$ & $\begin{array}{l}\text { Peer reviewed } \\
\text { journal }\end{array}$ & Non-profit & No \\
\hline $\begin{array}{l}\text { García-Sempere } \\
2005\end{array}$ & Spain & $21 / 38(55 \%)$ & Multiple & 2003-04 & Questionnaires & $\begin{array}{l}\text { Peer reviewed } \\
\text { journal }\end{array}$ & Government & Not reported \\
\hline Hemminki 2010 & Finland & $\begin{array}{l}\text { Questionnaires: } \\
55 / 85(65 \%) ; \\
\text { websites: } 13\end{array}$ & Multiple & 2003 & $\begin{array}{l}\text { Questionnaires, } \\
\text { websites }\end{array}$ & $\begin{array}{l}\text { Peer reviewed } \\
\text { journal }\end{array}$ & Government & No \\
\hline Jones 2008 & UK & 246 & Multiple & 2007 & $\begin{array}{l}\text { Websites (patient } \\
\text { groups and } \\
\text { pharmaceutical } \\
\text { companies) }\end{array}$ & $\begin{array}{l}\text { Peer reviewed } \\
\text { journal }\end{array}$ & Government & Not reported \\
\hline Jørgensen 2004 & $\begin{array}{l}\text { Various (Australia, } \\
\text { Canada, Denmark, } \\
\text { New Zealand, Norway, } \\
\text { Sweden, UK, US) }\end{array}$ & $\begin{array}{l}16(n=13 \text { advocacy } \\
\text { groups; } n=3 \text { con- } \\
\text { sumer groups) }\end{array}$ & Breast cancer & $\begin{array}{l}2002 \text { (websites, } \\
\text { funding information); } \\
1998 \text { (pamphlets, } \\
\text { some positions) }\end{array}$ & $\begin{array}{l}\text { Websites, follow-up } \\
\text { queries to patient } \\
\text { groups, patient } \\
\text { information pamphlets }\end{array}$ & $\begin{array}{l}\text { Peer reviewed } \\
\text { journal }\end{array}$ & $\begin{array}{l}\text { No funding } \\
\text { received }\end{array}$ & No \\
\hline Kopp 2018 & US & 1215 & Multiple & 2015 & $\begin{array}{l}\text { Websites (patient } \\
\text { groups and } \\
\text { pharmaceutical } \\
\text { companies), tax records }\end{array}$ & Report & Non-profit & No \\
\hline $\operatorname{Lin} 2017$ & US & $\begin{array}{l}\text { 30; questionnaire: } \\
26 / 30(87 \%)\end{array}$ & Multiple & 2016 & $\begin{array}{l}\text { Websites, tax records, } \\
\text { questionnaires, annual } \\
\text { reports }\end{array}$ & $\begin{array}{l}\text { Peer reviewed } \\
\text { journal }\end{array}$ & Not reported & No \\
\hline Marshall 2006 & US & 29 & Multiple & 2006 & $\begin{array}{l}\text { Websites, tax records, } \\
\text { questionnaires }\end{array}$ & Lay press & $\begin{array}{l}\text { Media (New } \\
\text { Scientist) }\end{array}$ & Not reported \\
\hline McCoy 2017 & US & 104 & Multiple & 2016 & Tax records, websites & $\begin{array}{l}\text { Peer reviewed } \\
\text { journal }\end{array}$ & Not reported & Yes \\
\hline Mosconi 2003 & Italy & 67 & Breast cancer & 1998-99 & Questionnaires & $\begin{array}{l}\text { Peer reviewed } \\
\text { journal }\end{array}$ & Non-profit & No \\
\hline $\begin{array}{l}\text { O’Donovan } \\
\text { 2007t† }\end{array}$ & Ireland & $112 / 167(67 \%)$ & Multiple & 2004 & Questionnaires & $\begin{array}{l}\text { Peer reviewed } \\
\text { journal }\end{array}$ & Non-profit & Not reported \\
\hline Perehudoff 2010 & Europe & 23 & Multiple & 2010 & $\begin{array}{l}\text { Websites (patient } \\
\text { groups and } \\
\text { pharmaceutical } \\
\text { companies), Google } \\
\text { searches, direct email } \\
\text { communication with } \\
\text { patient groups }\end{array}$ & Report & $\begin{array}{l}\text { Government } \\
\text { and non-profit }\end{array}$ & No \\
\hline Perehudoff 2011 & Europe & $\begin{array}{l}\text { Questionnaire: } \\
\text { 12/22 (55\%); pol- } \\
\text { icy analysis: } 14 / 22 \\
(64 \%)\end{array}$ & Multiple & $2009-10$ & $\begin{array}{l}\text { Websites (patient } \\
\text { groups and } \\
\text { pharmaceutical } \\
\text { companies), } \\
\text { questionnaires, } \\
\text { published policies }\end{array}$ & Report & $\begin{array}{l}\text { Government } \\
\text { and non-profit }\end{array}$ & No \\
\hline Pinto 2016 & Australia & $61 / 114(54 \%)$ & $\begin{array}{l}\text { Rare dis- } \\
\text { eases }\end{array}$ & 2013-14 & Questionnaires & $\begin{array}{l}\text { Peer reviewed } \\
\text { journal }\end{array}$ & $\begin{array}{l}\text { No funding } \\
\text { received }\end{array}$ & No \\
\hline Rose 2017 & US & $289 / 439(66 \%)$ & Multiple & 2013-14 & Questionnaires & $\begin{array}{l}\text { Peer reviewed } \\
\text { journal }\end{array}$ & Non-profit & Yes \\
\hline Rothman 2011 & US & 161 & Multiple & 2007-09 & $\begin{array}{l}\text { Websites, } \\
\text { pharmaceutical } \\
\text { company's grant registry }\end{array}$ & $\begin{array}{l}\text { Peer reviewed } \\
\text { journal }\end{array}$ & Non-profit & Not reported \\
\hline Schubert 2006 & Germany & 8 & Multiple & Not reported & $\begin{array}{l}\text { Websites, } \\
\text { questionnaires and } \\
\text { interviews, magazines } \\
\text { from patient groups }\end{array}$ & Report & Not reported & Not reported \\
\hline
\end{tabular}




\begin{tabular}{|c|c|c|c|c|c|c|c|c|}
\hline Study* & $\begin{array}{l}\text { Location of study } \\
\text { sample }\end{array}$ & $\begin{array}{l}\text { No of patient } \\
\text { groupst }\end{array}$ & $\begin{array}{l}\text { Disease } \\
\text { focus } ¥\end{array}$ & $\begin{array}{l}\text { Year of data } \\
\text { collection }\end{array}$ & $\begin{array}{l}\text { Data collection } \\
\text { methods§ }\end{array}$ & $\begin{array}{l}\text { Publication } \\
\text { type }\end{array}$ & $\begin{array}{l}\text { Funding } \\
\text { source }\end{array}$ & $\begin{array}{l}\text { Author } \\
\text { conflicts of } \\
\text { interest? }\end{array}$ \\
\hline $\begin{array}{l}\text { van Rijn van } \\
\text { Alkmade } 2005\end{array}$ & The Netherlands & $96 / 219$ (44\%) & Multiple & 2004 & $\begin{array}{l}\text { Questionnaires, annual } \\
\text { reports }\end{array}$ & Report & Government & Not reported \\
\hline Vitry 2011 & Australia & 135 & Multiple & 2011 & $\begin{array}{l}\text { Websites (patient } \\
\text { groups and } \\
\text { pharmaceutical } \\
\text { companies) }\end{array}$ & $\begin{array}{l}\text { Conference } \\
\text { presentation }\end{array}$ & Non-profit & Not reported \\
\hline
\end{tabular}

FDA=US Food and Drug Administration.

*Study design: all cross sectional.

tNumber of patient groups included in our analysis; some studies included several samples. Response rate given if applicable.

†The term "multiple" for disease focus is used for studies that focused on patient groups that work on a range of clinical areas.

$\S$ Some studies used several data collection methods (eg, website analyses, questionnaires, interviews); only those used to collect data included in this systematic review are reported. If not

further specified, websites and questionnaires refer to patient groups as a data source.

१Only with pharmaceutical or device industries.

**Baggott 2014 describes two studies, one of which is described in greater detail in Baggott 2005 (see row above); the listing for Baggott 2014 in this table covers only the second study.

t†A less comprehensive version of the same study conducted in 2005 was also identified.

for all the domains and six studies were considered to be of high quality for all the domains apart from one, which was judged to be unclear. For one domain, selection of statistical techniques, all included studies were considered to be of high quality because most of the analyses presented only descriptive statistics. The domain with the most studies judged to be of low quality $(n=7 / 26)$ relates to the provision of baseline information on study participants and setting (Q4). Overall, 17 (65\%) studies were judged to be of high quality and nine $(35 \%)$ of low quality. Supplementary file 3 presents the reasons for reviewers' judgment on all domains assessed to be of low quality or unclear.

\section{Prevalence of industry funding of patient groups}

Fifteen studies looked at prevalence of industry funding

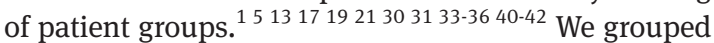
the studies into three categories, as shown in figure 3. Eleven studies looked at prevalence within a population based sample: eight focused on multiple diseases, with prevalence estimates ranging from $43 \%$ to $83 \%$, and three focused on a specific condition, with prevalence estimates ranging from $20 \%$ to $75 \%$. Four studies focused on a selected population of patient groups (eg, respondents to consultations or patient groups that interact with regulatory agencies); prevalence ranged from $34 \%$ to $75 \%$. Industry funding among patient groups varied greatly, from a few per cent of the total budget to almost the entire budget (table 3 ).

Supplementary file 4 shows that the 11 studies that looked at prevalence within a population based sample were included in a meta-analysis. We found a high level of heterogeneity that was not explained by any of the prespecified and post hoc subgroup analyses. Given the high level of unexplained heterogeneity, no summary estimate is presented.

\section{Number of industry sponsors and frequency of contact}

Four studies reported on the number of industry sponsors for each patient group. One study reported a median of seven industry sponsors (range 1-19) disclosed on patient group websites. ${ }^{42}$ Another study reported a median of one industry sponsor (range

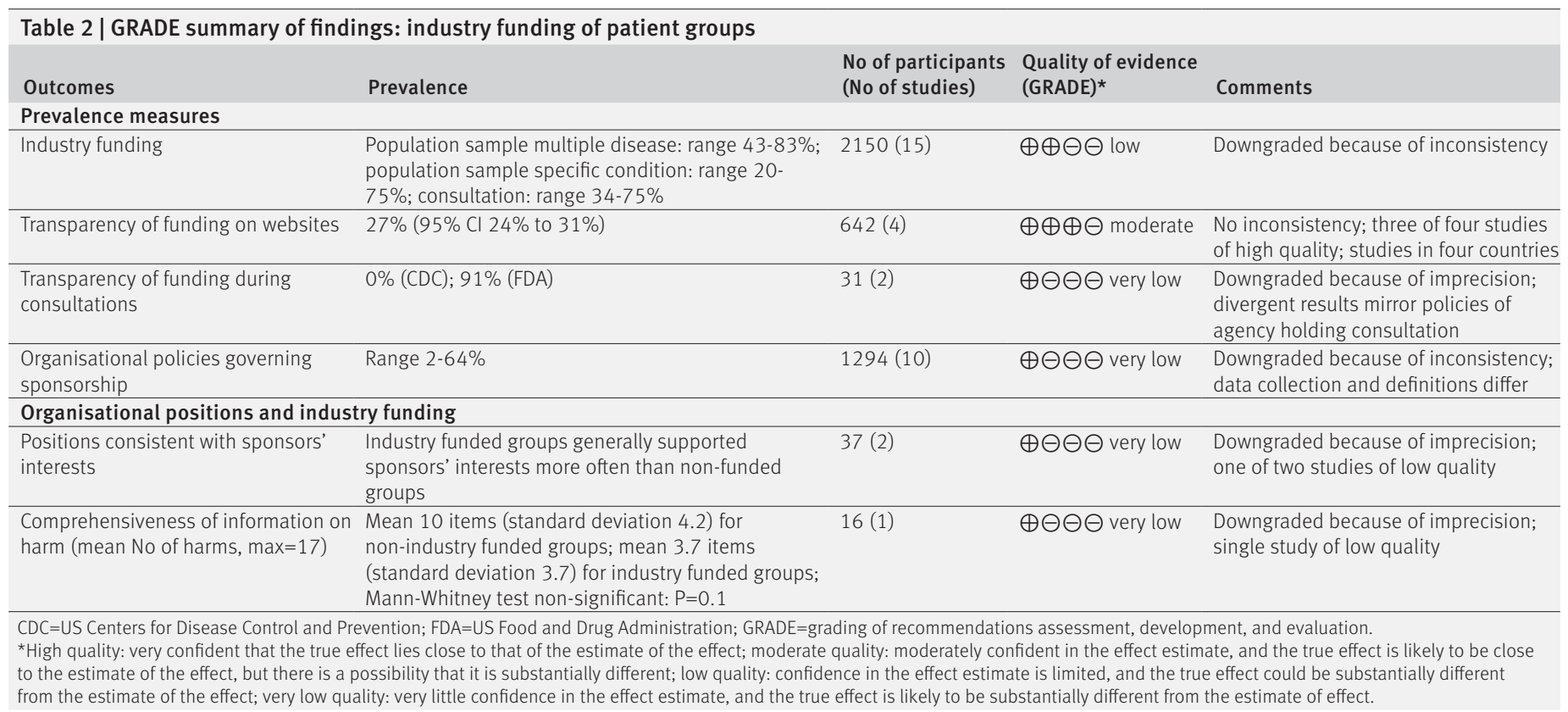




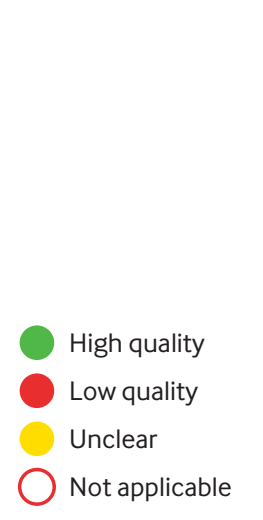

Anonymous 2003

Abola 2016a

Abola 2016b

Baggott 2005

Baggott 2014*

Ball 2006

Claypool 2016

Colombo 2012

Garcia Sempere 2005

Hemminki 2010

Jones 2008

Jorgensen 2004

Kopp 2018

Lin 2017

Marshall 2006

McCoy 2017

Mosconi 2003

O'Donovan 2007

Perehudoff 2010

Perehudoff 2011

Pinto 2016

Rose 2017

Rothman 2011

Schubert 2006

van Rijn van Alkmade 2005

Vitry 2011
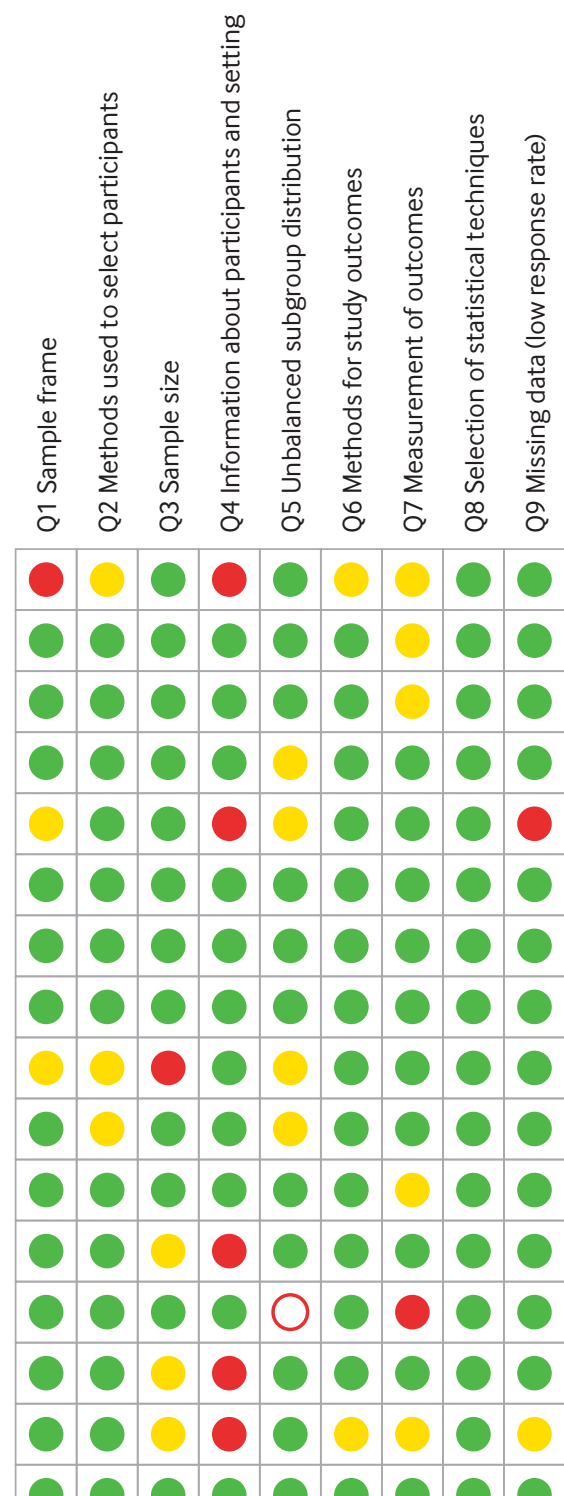

000000000 \begin{tabular}{lllllllllll}
\hline & 0 & 0 & 0 & 0 & 0 & 0 & 0 & 0 \\
\hline & 0 & 0 & 0 & 0 & 0 & 0 & 0 \\
\hline
\end{tabular}

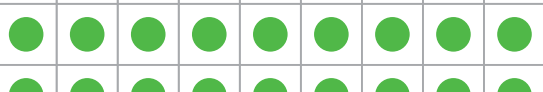
\begin{tabular}{llllllllll}
\hline & 0 & 0 & 0 & 0 & 0 & 0 & 0 & 0 \\
\hline & 0 & 0 & 0 & 0 & 0 & 0 & 0 & 0
\end{tabular}

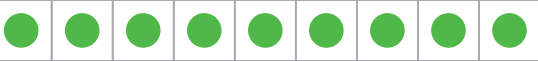
\begin{tabular}{llllllllll}
\hline & 0 & 0 & 0 & 0 & 0 & 0 & 0 & 0 \\
\hline
\end{tabular} \begin{tabular}{lllllllllll|}
\hline & 0 & 0 & 0 & 0 & 0 & 0 & 0 & 0 \\
\hline & 0 & 0 & 0 & 0 & 0 & 0 & 0 & 0 \\
\hline
\end{tabular}

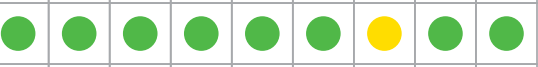
\begin{tabular}{|l|l|l|l|l|l|l|l|l|}
\hline 0 & 0 & 0 & 0 & 0 & 0 & 0 & 0 & 0 \\
\hline & 0 & 0 & 0 & 0 & 0 & 0 & 0 & 0 \\
\hline & 0 & 0 & 0 & 0 & 0 & 0 & 0 & 0 \\
\hline
\end{tabular}

Fig 2 | Quality appraisal of included studies. *Baggott (2014) describes two studies, one of which is described in greater detail in Baggott (2005), given in row above

0-21) disclosed on patient group websites, although this figure increased to a median of six industry sponsors (range 0-38) in information provided in annual reports. ${ }^{5}$ A study in the United Kingdom found that 140 (57\%) of 246 patient groups received funding from only one company, ${ }^{14}$ whereas in a Dutch study, $29(71 \%)$ of 41 patient groups were funded by two or more companies. ${ }^{31}$

Frequency of industry contacts (eg, number of meetings, phone calls) was reported in four studies. In two UK studies, 55 (45\%) of $123^{39}$ and $43(35 \%)$ of 122 groups reported at least quarterly contact with the pharmaceutical industry. ${ }^{32}$ A Dutch study reported on patient groups' responses to a question on how often they were contacted by companies in the past two years, $36(38 \%)$ of 96 groups were contacted on average 3.4 times. Reported reasons for communication included company requests to distribute an article on a drug, requests to promote a drug, and offers to produce information materials or fund awareness raising activities. This study also reported that $36(38 \%)$ of 96 patient groups had requested support from pharmaceutical companies in the past two years. ${ }^{31}$ A Finnish study asked groups about changes of cooperation with drug manufacturers over the past five years: $22(40 \%)$ of 55 reported no change, 18 (33\%) reported an increase, and five (9\%) a decrease. ${ }^{13}$

\section{Proportion of industry funded patient groups that} disclose information about this funding

Table 4 describes the proportion of industry funded patient groups that disclosed information about industry funding on their websites or in public consultations. Four studies (from Australia, Italy, the UK, and the US) analysed patient group websites and found that between a quarter and a third of the groups disclosed industry funding. ${ }^{12} 142937$ When we meta-analysed these four studies, the overall pooled proportion of groups that disclosed industry funding was $27 \%$ (95\% confidence interval $24 \%$ to $31 \%, I^{2}=0 \%$; fig 4). However, the four studies were published between 2008 and 2012, and disclosure of financial relationships might have changed since that period. Two studies of submissions to consultations in the US had the highest and lowest disclosure rates. Abola and Prasad analysed whether US Food and Drug Administration speakers at advisory committee meetings disclosed financial relationships and found a $91 \%$ disclosure rate ${ }^{30}$; whereas Lin and colleagues found no disclosures in submissions to a US Centers for Disease Control and Prevention consultation on opioid guidelines. ${ }^{19}$ Finally, the amount, use, and proportion of income derived from industry funding were rarely disclosed (table 4).

\section{Relationship between industry funding and organisational positions}

Four studies analysed the association between organisational positions and industry funding. Of these, three studies examined organisational positions versus industry funding, two of which included comparisons between industry funded and nonfunded groups. One study examined information 


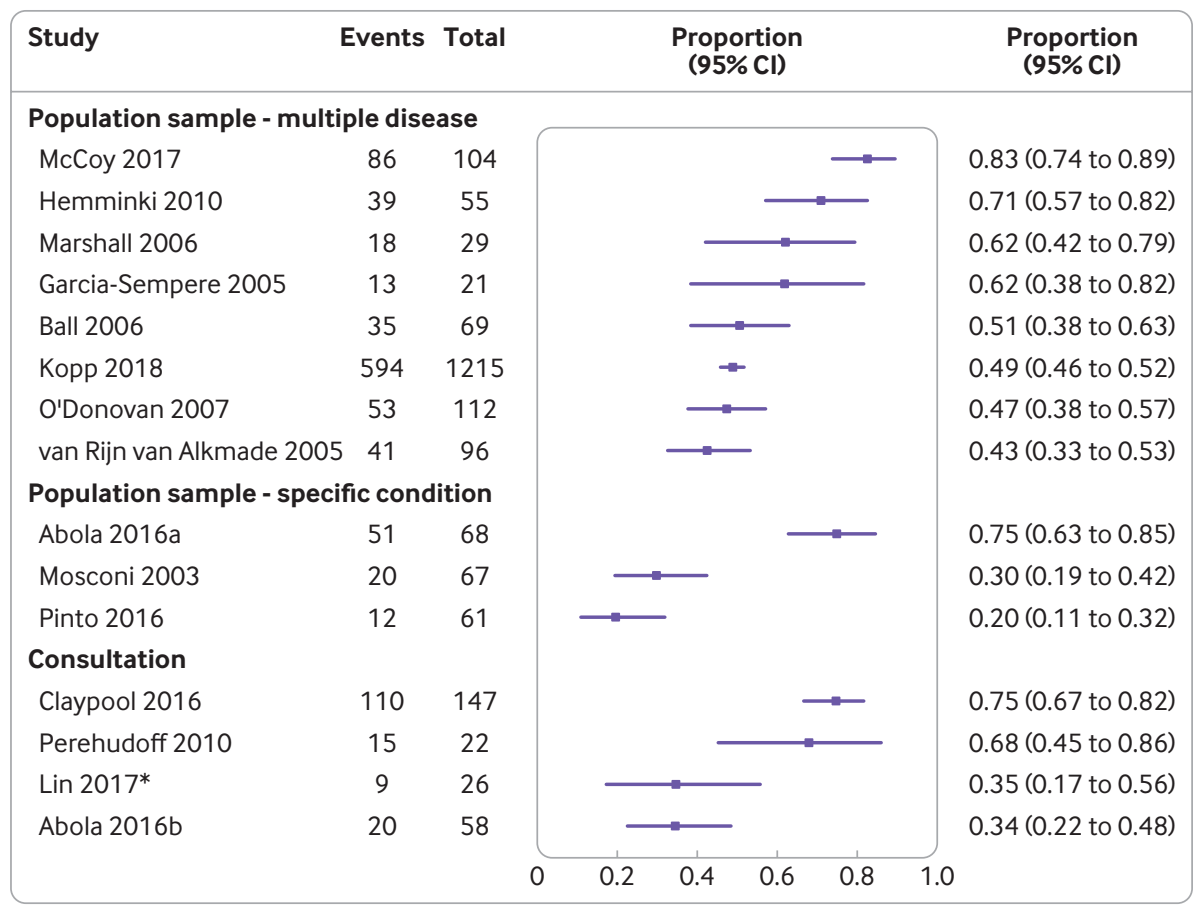

Fig 3 | Forest plot of prevalence of industry funding of patient groups. *Data received from authors

quality among industry funded versus non-funded groups.

Perehudoff surveyed patient and consumer organisations that had official relations with the European Medicines Agency. This study examined the opinions of these organisations on a controversial European legislative proposal on industry provided patient information. ${ }^{20}$ Specific elements of this proposal were interpreted as partial introduction of direct to consumer advertising in Europe, whereas other aspects were less controversial. ${ }^{43}$ Legislative

\begin{tabular}{|c|c|}
\hline Study details (No of patient groups) & Industry funding \\
\hline \multicolumn{2}{|l|}{ Range } \\
\hline Hemminki $2010(n=21)$ & $€ 300-58000$ \\
\hline \multicolumn{2}{|l|}{ Mean amount } \\
\hline Kopp $2018(n=594)$ & 2015: \$195305* \\
\hline Perehudoff $2010(n=14)$ & 2006: $€ 185500$ \\
\hline Perehudoff $2010(n=13)$ & 2007: $€ 282090 ; 2008: € 321230$ \\
\hline van Rijn van Alkmade $2005(n=16)$ & 2002: €29418t; 2003: €56670t \\
\hline \multicolumn{2}{|l|}{ Mean proportion of funding (\%) } \\
\hline Perehudoff $2010(n=14)$ & 2006: 47 \\
\hline Perehudoff $2010(n=13)$ & 2007: 51; 2008: 57 \\
\hline van Rijn van Alkmade $2005(n=16)$ & 2002: 11.1; $2003: 12.6$ \\
\hline \multicolumn{2}{|l|}{ Median (IQR) proportion of funding (\%) } \\
\hline Rose $2017(n=156)$ & $45(0-100)$ \\
\hline \multicolumn{2}{|c|}{ No of groups (\%) with industry funding $\geq 20 \%$} \\
\hline Hemminki 2010 & $4 / 20(20)$ \\
\hline Kopp 2018 & $15 / 594(3)$ \\
\hline Marshall 2006 & $7 / 24(29)$ \\
\hline \multicolumn{2}{|c|}{ No of groups (\%) with industry funding $\geq 10 \%$} \\
\hline McCoy 2017 & $11 / 59(19)$ \\
\hline \multicolumn{2}{|c|}{ No of groups (\%) with industry funding $\geq \$ 1 \mathrm{~m}$} \\
\hline McCoy 2017 & $23 / 59(39)$ \\
\hline $\begin{array}{l}£ 1.00=\$ 1.32, € 1.18 . I Q R=\text { interquartile ran } \\
\star \\
\text { * Own calculation. } \\
\dagger \text { Amounts under } € 1000 \text { for each organisati }\end{array}$ & \\
\hline
\end{tabular}

change to increase the industry's role was supported by all six (100\%) industry funded groups compared with none of five $(0 \%)$ non-funded groups. For two other outcomes, support for broadcast advertising and mention of brands in disease awareness advertising, little difference was seen between industry funded and non-funded groups: $17 \%$ versus $20 \%$, and $33 \%$ versus $20 \%$, respectively.

The second study by Lin and colleagues analysed links between funding from opioid manufacturers and statements of professional organisations and patient groups when consulting during guideline development aiming to minimise harms of opioid use developed by the US Centers for Disease Control and Prevention. ${ }^{19}$ According to supplementary data provided by the authors, most non-industry funded groups (15 of 17 , $88 \%$ ) supported the guideline recommendations; in contrast, less than half of the opioid manufacturer funded patient groups (four of nine, 44\%) were supportive and the remainder (five of nine, 56\%) were unsupportive. ${ }^{19}$

The third study examined prevalence of industry funding among patient groups that opposed a proposal to reduce Medicare Part B drug costs. ${ }^{33}$ This proposal included changes to reimbursement that minimised financial incentives to prescribe more expensive drugs, and introduction of value based purchasing tools tying drug prices to patient health outcomes. ${ }^{45}$ In total, 110 of $147(75 \%)$ of the patient groups that sided with pharmaceutical companies and opposed the proposal had received industry funding. ${ }^{33}$

Finally, one study explored the association between industry funding and information quality. ${ }^{18}$ The authors analysed the information about mammography screening on the websites of 16 consumer advocacy 


\begin{tabular}{|c|c|c|c|c|}
\hline Study & $\begin{array}{l}\text { Organisations that } \\
\text { disclosed funding }\end{array}$ & $\begin{array}{l}\text { Amount } \\
\text { disclosed }\end{array}$ & $\begin{array}{l}\text { Proportion of } \\
\text { income disclosed }\end{array}$ & Use disclosed \\
\hline \multicolumn{5}{|l|}{ On websites } \\
\hline Vitry 2011 & $25 / 78(32)$ & - & - & - \\
\hline Colombo 2012 & 46/157 (29) & $3 / 157(2)$ & $0 / 157(0)$ & 25/157 (16) \\
\hline Jones 2008 & $64 / 246(26)$ & $14 / 246(6)$ & 4/246 (2) & $18 / 246(7)$ \\
\hline Rothman 2011* & 40/161(25) & $1 / 161$ (1) & - & - \\
\hline \multicolumn{5}{|l|}{ In consultations } \\
\hline Abola 2016b & 20/22 (91) & - & - & - \\
\hline Lin 2017 & $0 / 9(0) \dagger$ & - & - & - \\
\hline
\end{tabular}

groups. They measured the comprehensiveness of information on potential harms of mammography, including risks of false positives and overdiagnosis, by using a checklist of 17 information items. ${ }^{18}$ The mean number of information items was 3.7 (standard deviation 3.7) for industry funded groups and 10 (standard deviation 4.2) for non-industry funded groups. We compared the number of information items provided with a Mann-Whitney test and the result was not statistically significant $(\mathrm{P}=0.1)$.

\section{Policies that govern corporate sponsorship}

None of the included studies compared organisational policies (eg, code of conduct) of industry funded and non-industry funded groups. Because comparative data were unavailable, we report on a related outcome: prevalence of organisational policies that govern corporate sponsorship. Estimates of prevalence of organisational policies ranged from $2 \%$ to $64 \%$ (fig

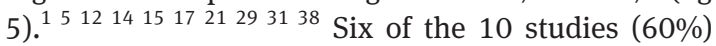
had a prevalence below $10 \%$. Among studies of high quality, the highest prevalence of policies was reported in two 2017 US studies, ${ }^{115}$ which possibly reflects recent shifts in disclosure of financial relationships with industry. The meta-analysis found a high level of heterogeneity that was not explained by the subgroup analysis (supplementary file 4).

Financial conflicts of interest among governing and advisory bodies

One of the primary outcomes in our protocol was to analyse how often industry employees or people with financial links to companies were present on the governing and advisory boards of industry funded and non-industry funded groups. Comparative data were unavailable. However, two studies reported on a related outcome, the proportion of patient groups with industry employees or people with financial conflicts of interest on the governing or advisory board. A German study found that five of eight groups had a scientific advisory board with listed members; of these, all five (100\%) had members with financial ties with pharmaceutical companies. ${ }^{22}$ A recent US study reported that 37 of 104 (36\%) patient groups had at least one drug, device, or biotechnology company executive on the board.

\section{Presence of industry logos and advertising}

Three articles reported on the prevalence of industry logos on patient group websites. ${ }^{512} 31$ Company logos were displayed on 26 of 157 (17\%) websites of Italian patient groups, ${ }^{12}$ on 23 of 69 (33\%) websites of major national and international patient groups, ${ }^{5}$ and on 21 of 41 (51\%) websites of Dutch patient groups. ${ }^{31}$ Three studies reported on the prevalence of banner advertisements or links to industry websites ${ }^{5}{ }^{12}$; all found they were present to some extent, although frequencies differed, ranging from $11 \%$ to $30 \%$ of the websites analysed. ${ }^{5} 12$ A German study analysed magazines for members and found that six of seven (86\%) had direct advertisements, such as industry logos or links to industry websites; the analysis of patient group websites showed that four of eight (50\%) had logos or links to industry websites. ${ }^{22}$

\section{Discussion}

\section{Key findings}

Of the 26 studies included in this systematic review, 11 included estimates of the prevalence of industry funding within a population based sample, which ranged from $20 \%$ to $83 \%$. Four studies focused on a selected population of patient groups (eg, respondents to consultations or patient groups that interact with regulatory agencies); prevalence ranged from 34\% to $75 \%$. Most of the included studies did not provide data on the amount and proportion of funding that came from industry. Among patient organisations that received industry funding, 27\% (95\% confidence interval $24 \%$ to $31 \%$ ) disclosed this information on their websites. However, all four studies were

\begin{tabular}{|c|c|c|c|c|c|}
\hline Study & Events & Total & $\begin{array}{l}\text { Proportion } \\
(95 \% \mathrm{CI})\end{array}$ & $\begin{array}{l}\text { Weight } \\
\text { (\%) }\end{array}$ & $\begin{array}{l}\text { Proportion } \\
(95 \% \mathrm{Cl})\end{array}$ \\
\hline Vitry 2011 & 25 & 78 & & 12.2 & $0.32(0.22$ to 0.44$)$ \\
\hline Colombo 2012 & 46 & 157 & & 24.5 & $0.29(0.22$ to 0.37$)$ \\
\hline Jones 2008 & 64 & 246 & & 38.3 & $0.26(0.21$ to 0.32$)$ \\
\hline Rothman 2011 & 40 & 161 & & 25.1 & 0.25 (0.18 to 0.32$)$ \\
\hline Random effects model & & 642 & 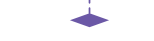 & 100.0 & $0.27(0.24$ to 0.31$)$ \\
\hline
\end{tabular}

Fig 4 | Forest plot of proportion of industry funded patient groups that disclosed information about this funding on their websites 


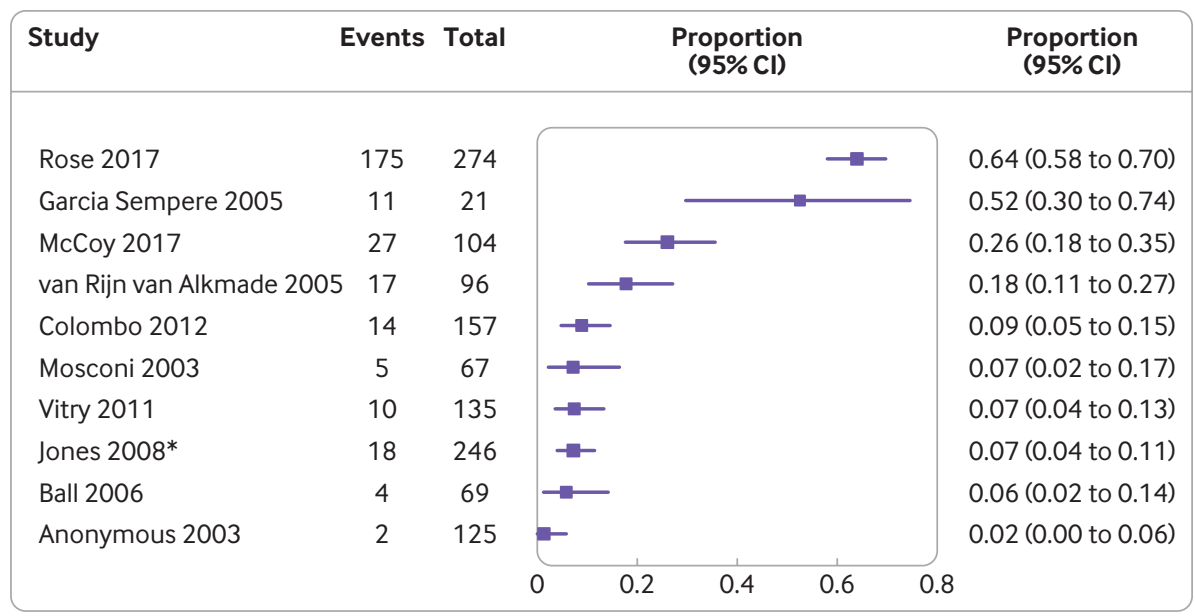

Fig 5 | Forest plot of prevalence of policies governing corporate sponsorship. *Data received from authors

published between 2008 and 2012, and disclosure of financial relationships might have changed since that period. In submissions to governmental consultations, two studies showed very different disclosure rates $(0 \%$ and 91\%), which appeared to reflect differences in the relevant government agency's disclosure policies. Few patient groups had formal policies that governed corporate sponsorship.

Four studies analysed the relationship between organisational positions and industry funding. These studies addressed a range of highly controversial issues: overdiagnosis, pharmaceutical advertising, harm from opioid use, and high drug costs. All four studies represent situations in which a conflict existed between the interests of commercial sponsors and the interests of patients or the public. For example, the study by Claypool focused on groups that opposed a proposal aimed at decreasing the prescription of high cost drugs when less expensive and equally effective drugs are available. ${ }^{33}$ Access to equally effective but less costly drugs is in patients' interests because it improves affordability. The data available from the four studies point to positions reflective of sponsors' interests. However, this finding should be interpreted with caution because three of the studies had small sample sizes and all the studies focused on a single policy or health issue. Additionally, this association between the positions of sponsored groups and sponsors does not necessarily reflect an influence by industry on a group's agenda. Sponsors could have selectively funded groups with positions that were closely aligned with their own interests.

\section{Strengths and limitations of study}

This systematic review summarises published data on industry funding of patient groups. We registered our protocol before conducting the review, undertook a comprehensive search of multiple databases with no restrictions on language or publication type, searched the reference list of included studies, and contacted experts in the field to identify additional studies for inclusion.
Our review had several limitations. Firstly, all the studies were conducted in high income countries (apart from one study that included data from South Africa, an upper middle income country), thus our findings might not be generalisable to middle or low income settings. Secondly, although most included studies relied on more than one data source, the information was mainly publicly disclosed and self reported, which could underestimate the true prevalence of industry funding. Thirdly, we relied on how the included studies defined pharmaceutical and medical device companies. In many cases definitions were quite broad, which might have introduced some inconsistencies. Moreover, the focus of this systematic review was specifically on relationships between patient groups and pharmaceutical and device companies; it is possible that other conflicts are also relevant for specific groups within this sector, such as relationships with the food industry or with private health insurance providers. Fourthly, for two outcomes (prevalence of industry funding and prevalence of policies) we could not present summary estimates because of the high level of heterogeneity, which was not explained by any of the subgroup analyses. Heterogeneity could be because data collection methods differed considerably among included studies. For example, some studies relied on a single source of information (eg, the groups' websites) to assess prevalence rates, while others used multiple sources of data, including websites of patient groups and pharmaceutical companies, questionnaires, and tax records. Survey response rates ranged from 39\% to $87 \%$. Fifthly, the checklist for prevalence studies used to assess study quality includes items relevant to broader study quality, reporting quality, and risk of bias. This broader set of criteria may have affected our ability to measure the methodological quality of the included studies. Finally, not all the included studies were peer reviewed.

\section{Implications for research}

We found limited research on the association between industry funding and organisational policy positions. Patient groups play an important part in education, 
health policy, and advocacy, therefore more research on the potential impact of industry funding on the groups' activities is needed. Moreover, future research should use multiple sources of information to better estimate the prevalence of industry funding. Because of inadequate financial transparency, studies that rely only on self reported information could underestimate the extent of sponsorship. Increased transparency requirements of pharmaceutical industry funding of patient groups ${ }^{46}$ could lead to more accurate estimates. Similar legislation to the US Sunshine Act should be implemented in other jurisdictions and expanded to cover industry payments to patient groups. ${ }^{47}$ Moreover, our systematic review shows a lack of research on this topic in low and middle income countries. Industry funding and influence could be even greater in jurisdictions with fewer local resources, and so these areas could be important for future research.

\section{Implications for policy and practice}

Our systematic review showed that pharmaceutical industry funding of patient groups is common in many high income countries. We recognise that industry funding might be the only source of income for some groups. However, increasing evidence suggests that industry sponsorship can create bias in medical research and clinical practice, ${ }^{48} 49$ and industry sponsorship of patient groups could contribute to similar biases. The pharmaceutical industry is likely to prioritise funding of groups whose views are aligned to their own interests. ${ }^{3}$ Patient groups are powerful advocates with influence over health policy. If industry funded patient groups are more likely to flourish and to have the most influence over the health sector, this could lead to widespread commercial biases in the representation of patients' interests, with misalignment between the public's health priorities and advocacy driven health policy. Alternative funding mechanisms could be explored. Consideration could also be given to whether there is a greater need for mechanisms for public financing of patient groups; for example, provision of small grants that allow community organisations without corporate subsidies to participate in advocacy.

We found few studies that assessed links between funding status of patient groups and their health and policy positions, ${ }^{18-20} 33$ but the limited data available suggest positions reflective of sponsors' interests. Moreover, a recent analysis of patient groups that contributed to health technology assessments conducted by the National Institute for Health and Care Excellence (NICE) found that $72 \%$ had received funding by companies with products under consideration or their competitors. These findings raise concerns about the impact these conflicts of interest might have in approval of new health technologies in the UK. NICE was rarely aware of these financial relationships, and in nearly two thirds of cases, NICE's disclosure policy did not require declaration of these undisclosed conflicts of interest. ${ }^{50}$ Governmental agencies should develop robust guidelines to ensure financial transparency of the patient groups they interact with. These guidelines should include monitoring procedures and strategies to manage the disclosed conflicts of interest, and policies that ensure patient groups without industry funding are consulted when making decisions. Full funding disclosure would assist people who listen to patient group voices (eg, patients, health professionals, and policy makers) in the critical evaluation of those groups' practices.

Disclosure might also have an important effect on the groups themselves by increasing their accountability in managing conflicts of interests and encouraging them to seek other sources of funding to maintain the public's trust. ${ }^{51}$ Two studies that examined disclosure in patient group submissions to consultations with US governmental agencies reported very different disclosure rates: $0 \%$ in submissions to the Centers for Disease Control and Prevention ${ }^{19}$ and $91 \%$ in submissions to the Food and Drug Administration. ${ }^{30}$ This finding suggests that the agencies' policies exert a strong influence on disclosure rates. Finally, we examined industry funding of patient groups because of the limited attention paid to conflicts of interest in this sector. However, financial conflicts of interest are a systemic challenge for healthcare today and they can have an impact on many other stakeholders, such as researchers, health professionals, and medical societies. ${ }^{52} 53$

\section{Conclusion}

This systematic review shows that pharmaceutical industry funding of patient groups is common in many high income countries and clinical areas. The extent of industry funding of patient groups in low to middle income countries is unknown because only one study included data from South Africa, an upper middle income country. Few patient groups have policies that govern corporate sponsorship. Transparency about corporate funding is also inadequate. The few studies that assessed the link between policy positions and funding status raise concerns about industry influence. In conclusion, we encourage patient groups to critically evaluate the role of industry funding on their operations. Greater transparency in reporting of industry funding and policy development to govern corporate sponsorship are steps that are clearly needed and easy to implement. In the long term, we would recommend a broader discussion about industry funding in the patient group sector, among patient groups themselves and in the wider society, and exploration of alternative funding mechanisms.

We thank Paolo Vercellini (Università degli Studi di Milano, Italy) for his input on the protocol. Camilla Van Wijk and Katrina Perehudoff assisted with translation, data extraction, and quality assessment of a Dutch study. ${ }^{31}$ Marc Torka and Yasmin Kroeger assisted with translation of a German study. ${ }^{22}$ Sharon Batt (cofounder of Breast Cancer Action Quebec, executive board member of the Nova Scotia Health Coalition and current "community champion" for the Public Awareness Committee of the Canadian Deprescribing Network) read the manuscript and provided feedback.

Contributors: AF, CC, PM, EL, and BM conceived the study idea. DMS conducted the literature search. AF, LP, CC, PM, EL, MPF, GB, and BM screened abstracts and full texts and acquired the data. CMK and 
$\mathrm{CL}$ analysed the data. AF wrote the first draft of the manuscript. All authors edited drafts of this article and approved the final version. BM is the guarantor. The corresponding author attests that all listed authors meet authorship criteria and that no others meeting the criteria have been omitted.

Funding: There is no specific funding for this study. AF was supported as a postdoctoral fellow by the National Health and Medical Research Council of Australia (NHMRC), project grant No 1122332. CMK was supported as a postdoctoral fellow by the NHMRC, project grant No 1139997.

Competing interests: All authors have completed the ICMJE uniform disclosure form at www.icmje.org/coi_disclosure.pdf and declare: no support from any organisation for the submitted work; PM and CC report an unconditional grant from the Smith Kline Foundation outside the submitted work; PM and CC are authors of some of the studies included in the review and were not involved in extracting data from or assessing the quality of their own studies; PM is a member of the Board of Europa Donna, the European Breast Cancer Coalition; BM is a member of the European network of Health Action International (HAlEurope) and given this relationship she was not involved in extracting data from or assessing the quality of the two studies published by HAl-Europe 2041 : BM acted as an expert witness on behalf of plaintiffs in a Canadian class action suit on cardiovascular risks of testosterone; the remaining authors declare no other relationships or activities that could appear to have influenced the submitted work.

Ethical approval: Not required.

Data sharing: All data relevant to the study are included in the article or uploaded as supplementary information.

The senior author (BM) affirms that the manuscript is an honest, accurate, and transparent account of the study being reported; that no important aspects of the study have been omitted; and that any discrepancies from the study as planned have been explained.

Dissemination to participants and related patient and public communities: Systematic review results will be disseminated to patient groups through publicly accessible conferences, workshops, and the media.

This is an Open Access article distributed in accordance with the Creative Commons Attribution Non Commercial (CC BY-NC 4.0) license, which permits others to distribute, remix, adapt, build upon this work non-commercially, and license their derivative works on different terms, provided the original work is properly cited and the use is noncommercial. See: http://creativecommons.org/licenses/by-nc/4.0/.

1 McCoy MS, Carniol M, Chockley K, Urwin JW, Emanuel EJ, Schmidt H. Conflicts of interest for patient-advocacy organizations. N Engl f Med 2017;376:880-5. doi:10.1056/NEJMsr1610625

2 Heywood M. South Africa's treatment action campaign: combining law and social mobilization to realize the right to health. J Hum Rights Pract 2009;1:14-36. doi:10.1093/ihuman/hun006

3 Moynihan R, Bero L. Toward a healthier patient voice: more independence, less industry funding. JAMA Intern Med 2017;177:350-1. doi:10.1001/jamainternmed.2016.9179

4 Herxheimer A. Relationships between the pharmaceutical industry and patients' organisations. BMJ 2003;326:1208-10. doi:10.1136 bmj.326.7400.1208

5 Ball DE, Tisocki K, Herxheimer A. Advertising and disclosure of funding on patient organisation websites: a cross-sectional survey. BMC Public Health 2006;6:201. doi:10.1186/1471-2458-6-201

6 Batt S. Who will support independent patient groups?BMJ 2014:349:g6306. doi:10.1136/bmi.g6306

7 European Patients' Academy (EUPATI). https://www.eupati.eu/

8 Medicines Australia. Working Together Guide 2008. https:// medicinesaustralia.com.au/community/working-together-guide/

9 Patient Think Tank EFPIA. Working together with patient groups. September 2017. https://www.efpia.eu/media/288492/workingtogether-with-patient-groups-23102017.pdf

10 WECAN. Guiding principles on reasonable agreements between patient advocates and pharmaceutical companies. October 2018.

11 Code of Practice between patient organisations and the healthcare industry. 2009. https://www.eurordis.org/sites/default/files/ thumbnails/0904-PO-Code\%20of\%20practice.pdf.

12 Colombo C, Mosconi P, Villani W, Garattini S. Patient organizations' funding from pharmaceutical companies: is disclosure clear, complete and accessible to the public? An Italian survey. PLoS One 2012;7:e34974. doi:10.1371/journal.pone.0034974

13 Hemminki E, Toiviainen HK, Vuorenkoski L. Co-operation between patient organisations and the drug industry in Finland. Soc Sci Med 2010;70:1171-5. doi:10.1016/j. socscimed.2010.01.005
14 Jones K. In whose interest? Relationships between health consumer groups and the pharmaceutical industry in the UK. Sociol Health Illn 2008;30:929-43 doi:10.1111/j.1467-9566.2008.01109 x

15 Rose SL, Highland J, Karafa MT, Joffe S. Patient advocacy organizations, industry funding, and conflicts of interest. JAMA Intern Med 2017:177:344-50. doi:10.1001/jamainternmed 2016.8443

16 Harris PA, Taylor R, Thielke R, Payne J, Gonzalez N, Conde JG. Research electronic data capture (REDCap)--a metadata-driven methodology and workflow process for providing translational research informatics support. J Biomed Inform 2009;42:377-81. doi:10.1016/j. jbi.2008.08.010

17 García-Sempere A, Artells I]. [Organization, functioning and expectations of organizations representing patients. Survey of key informants]. Gac Sanit 2005;19:120-6.

18 Jørgensen KJ, Gøtzsche PC. Presentation on websites of possible benefits and harms from screening for breast cancer: cross sectional study. BM/ 2004;328:148. doi:10.1136/bmj.328.7432.148

19 Lin DH, Lucas E, Murimi IB, Kolodny A, Alexander GC. Financia conflicts of interest and the Centers for Disease Control and Prevention's 2016 guideline for prescribing opioids for chronic pain. JAMA Intern Med 2017;177:427-8. doi:10.1001/ jamainternmed.2016.8471

20 Perehudoff A. The patient \& consumer voice and pharmaceutical industry sponsorship. 2011. https://www.rug.nl/research/ portal/files/37737412/31_Jan_2011_HAI_EUROPE_Research_ Article_Patient_consumer_voice_and_pharmaceutical_industry sponsorship1.pdf

21 Mosconi P. Industry funding of patients' support groups: declaration of competing interests is rare in Italian breast cancer associations. BMJ 2003;327:344. doi:10.1136/bmj.327.7410.344

22 Schubert K, Glaeske G. Einfluss des pharmazeutisch-industriellen Komplexes auf die Selbsthilfe. 2006. http://www.medi-info.ch/d/ data/data_13.pdf

23 Joanna Briggs Institute. Checklist for prevalence studies. https:// joannabriggs.org/research/critical-appraisal-tools.html

24 Guyatt GH, Oxman AD, Vist GE, et al, GRADE Working Group. GRADE: an emerging consensus on rating quality of evidence and strength of recommendations. BMJ 2008;336:924-6. doi:10.1136/ bmj.39489.470347.AD

25 DerSimonian R, Laird N. Meta-analysis in clinical trials. Control Clin Trials 1986;7:177-88. doi:10.1016/0197-2456(86)90046-2

26 Freeman MF, Tukey JW. Transformations related to the angular and the square root. Ann Math Stat 1950;21:607-11. doi:10.1214/ aoms/1177729756

27 Newcombe RG. Two-sided confidence intervals for the single proportion: comparison of seven methods. Stat Med 1998:17:857. 72. doi:10.1002/(SICI)1097-0258(19980430)17:8<857::AIDSIM777>3.0.CO;2-E

28 Higgins JPT, Thompson SG, Deeks JJ, Altman DG. Measuring inconsistency in meta-analyses. BM/ 2003;327:557-60. doi:10.1136/bmj.327.7414.557

29 Vitry A. Investigating the relationship between health consumer organisations and the pharmaceutical industry. PowerPoint presentation. 2019.

30 Abola MV, Prasad V. Characteristics and conflicts of public speakers at meetings of the Oncologic Drugs Advisory Committee to the US Food and Drug Administration. JAMA Intern Med 2016;176:389-91. doi:10.1001/jamainternmed.2015.7805

31 van Rijn van Alkemade EM. Sponsoring van patiëntenorganisaties door de farmaceutische industrie. DGV, Nederlands instituut voor verantwoord medicijngebruik. 2005.

32 Baggott R, Jones K. The voluntary sector and health policy: the role of national level health consumer and patients' organisations in the UK. Soc Sci Med 2014;123:202-9. doi:10.1016/j. socscimed.2014.07.016

33 Claypool R. Patients' groups and big pharma. Public Citizen 2016. https://www.citizen.org/wp-content/uploads/patients-groups-andbig-pharma-money-report.pdf

34 Kopp E, Lucas E, Lupkin S, Knight V. Pre \$cription For Power Investigating the relationships between patient advocacy groups and big pharma. 2018. https://khn.org/patient-advocacy/\#.

35 Marshall J, Aldhous P. Patient groups special: swallowing the best advice?New Sci 2006;192:18-22. doi:10.1016/S02624079(06)60831-2

36 Pinto D, Martin D, Chenhall R. The involvement of patient organisations in rare disease research: a mixed methods study in Australia. Orphane J Rare Dis 2016:11:2. doi:10.1186/s13023-016-0382-6

37 Rothman SM, Raveis VH, Friedman A, Rothman DJ. Health advocacy organizations and the pharmaceutical industry: an analysis of disclosure practices. Am I Public Health 2011;101:602-9. doi:10.2105/AJPH.2010.300027

38 Who's injecting the cash? Which? April 2003:24-5

39 Baggott R, Allsop J, Jones K. Speaking for patients and carers - health consumer groups and the policy process. Palgrave Macmillan, Basingstoke, 2005. 
40 O'Donovan O. Corporate colonization of health activism? Irish health advocacy organizations' modes of engagement with pharmaceutical corporations. Int J Health Serv 2007;37:711-33. doi:10.2190/ HS.37.4.h

41 Perehudoff K, Alves TL. Patient \& consumer organisations at the European Medicines Agency: Financial disclosure and transparency. 2010. https://www.rug.nl/research/portal/files/37737294/11 Aug_2010_Report_Patient_consumer_organisations_at_the_EMA. pdf

42 Abola MV, Prasad V. Industry funding of cancer patient advocacy organizations. Mayo Clin Proc 2016;91:1668-70. doi:10.1016/j. mayocp.2016.08.015

43 Velo G, Moretti U. Direct-to-consumer information in Europe: the blurred margin between promotion and information. Br J Clin Pharmacol 2008;66:626-8. doi:10.1111/j.13652125.2008.03283.x

44 Mulinari S. Regulating drug information in Europe: a pyrrhic victory for pharmaceutical industry critics? Sociol Health Illn 2013;35:76177. doi:10.1111/j.1467-9566.2012.01528x

45 Proposed Rule. Centers for Medicare \& Medicaid Services. 2016. https://www.regulations.gov/document?D=CMS-20160036-0002.

46 EFPIA. Code of Practice on the relationships between the pharmaceutical industry and patient organisations. 2011. https:// www.efpia.eu/media/24310/3c_efpia-code-of-practice-onrelationships-pharmapluspt-orgs.pdf

47 Physician Payments Sunshine Act, 111th Congress (2009-2010), Library of Congress; Washington, DC. https://www.congress.gov/ bill/111th-congress/senate-bill/301.

48 Dejong C, Aguilar T, Tseng C-W, Lin GA, Boscardin WJ, Dudley RA. Pharmaceutical industry-sponsored meals and physician prescribing patterns for Medicare beneficiaries. JAMA Intern Med 2016;176:1114-22. doi:10.1001/jamainternmed.2016.2765

49 Lundh A, Lexchin J, Mintzes B, Schroll JB, Bero L. Industry sponsorship and research outcome. Cochrane Database Syst Rev 2017;2:MR000033.

50 Mandeville KL, Barker R, Packham A, Sowerby C, Yarrow K, Patrick H. Financial interests of patient organisations contributing to technology assessment at England's National Institute for Health and Care Excellence: policy review. BMJ 2019;364:k5300. doi:10.1136/bmj. k5300

51 Sah S, Loewenstein G. Nothing to declare: mandatory and voluntary disclosure leads advisors to avoid conflicts of interest. Psychol Sci 2014:25:575-84 doi:10.1177/0956797613511824

52 Institute of Medicine. Conflict of interest in medical research, education, and practice. The National Academies Press, 2009.

53 Fabbri A, Gregoraci G, Tedesco D, et al. Conflict of interest between professional medical societies and industry: a cross-sectional study of Italian medical societies' websites [correction: BMJ Open 2016;6:e011124corr1]. BMJ Open 2016;6:e011124. doi:10.1136 bmjopen-2016-011124

Supplementary file 1: Search strategy Supplementary file 2: List of excluded studies Supplementary file 3: Quality assessment for prevalence studies

Supplementary file 4: Supplementary figures Supplementary file 5: Analysis code 